\title{
Pearls \& Oy-sters: Labyrinthine Infarction Mimicking Vestibular Neuritis
}

Hyun-Wook Nam, MD, Dallah Yoo, MD, Sun-Uk Lee, MD, Jeong-Yoon Choi, MD, PhD, Sungwook Yu, MD, PhD, and Ji-Soo Kim, MD, PhD

Neurology ${ }^{\circledR}$ 2021;97:787-790. doi:10.1212/WNL.0000000000012297

\section{Pearls}

- Acute unilateral audiovestibulopathy is often caused by inflammatory disorders involving the labyrinth.

- Vascular compromise of the inner ear rarely causes acute unilateral audiovestibulopathy.

- The flocculus and labyrinth share a vascular supply from the anterior inferior cerebellar artery.

\section{Oy-sters}

- Labyrinthine infarction may cause acute unilateral peripheral vestibulopathy and thus mimic vestibular neuritis.

- Concomitant labyrinthine infarction should be suspected in acute vestibular syndrome in patients with acute infarction in the territory of the anterior inferior cerebellar artery.

A 63-year-old man with a history of diabetes mellitus and hypertension presented with acute vertigo for 3 hours. The vertigo began abruptly while driving and was accompanied by a popping sound and fullness in the left ear that lasted only 10 seconds. The patient also had nausea and vomiting, yet denied positional aggravation of the vertigo or associated diplopia or hearing loss. He had no antecedent history of infection.

Examination showed spontaneous nystagmus beating rightward, upward, and clockwise (the upper poles of the eyes beating to the patient's right shoulder) without visual fixation (Figure, A). Saccades were normal, but smooth pursuit seemed impaired to the right. The patient did not show directionchanging gaze-evoked nystagmus (GEN) or skew deviation. Hearing was decreased on the left side on finger rub test. Video head-impulse tests (HITs) were positive for the left horizontal canal (HC) with a decreased gain and overt saccades, but normal for the vertical canals (Figure, B; video). Horizontal saccades were normal. After correction of the spontaneous nystagmus, smooth pursuit at a peak target velocity of $20^{\circ} \mathrm{s}$ was normal with a gain of 0.79 to the right and 0.71 to the left. Bithermal caloric tests showed a left canal paresis of 29\%. Fundus photography showed abnormal extorsion of the left eye (Figure, C). The subjective visual vertical (SVV) was tilted to the left only during left-eye viewing $\left(-3.3^{\circ}\right.$, normal range -3.8 to $\left.3.1^{\circ}\right)$, but normal during right-eye $\left(-2.7^{\circ}\right.$, normal range -3.1 to $\left.3.0^{\circ}\right)$ or binocular viewing $\left(-2.4^{\circ}\right.$, normal range -2.4 to $\left.2.6^{\circ}\right)$. Rotatory chair tests documented decreased gains of the horizontal vestibulo-ocular reflex (VOR) without an asymmetry, as well as phase leads during sinusoidal harmonic acceleration at frequencies from 0.01 to $0.04 \mathrm{~Hz}$. The patient showed a high-tone sensorineural hearing loss in both ears, slightly more prominent in the left ear (Figure, D). Speech discrimination was normal. Results of cervical and ocular vestibular-evoked myogenic potentials and auditory evoked potentials were also unrevealing. MRIs disclosed an acute infarction involving the left flocculus (Figure, E). Magnetic resonance angiography and perfusion CT were normal. The patient was placed on $100 \mathrm{mg}$ of aspirin, $75 \mathrm{mg}$ of clopidogrel, and $40 \mathrm{mg}$ of atorvastatin. The vertigo and vomiting improved over the following days along with resolution of the spontaneous nystagmus.
Correspondence

Dr. Lee

sulee716@gmail.com
MORE ONLINE

$\checkmark$ Video

From the Department of Neurology (H.-W.N., S.-U.L., S.Y.), Korea University Medical Center; Department of Neurology (D.Y.), Kyung Hee University Hospital; Dizziness Center, Clinical Neurosience Center, and Department of Neurology (J.-Y.C., J.-S.K.), Seoul National University Bundang Hospital, Seongnam; Department of Neurology (D.Y., S.-U.L., J.-Y.C., J.-S.K.), Seoul National University College of Medicine, Seoul; and Department of Neurology (S.Y.), Korea University College of Medicine, Seoul, South Korea.

Go to Neurology.org/N for full disclosures. Funding information and disclosures deemed relevant by the authors, if any, are provided at the end of the article. 


\section{A}

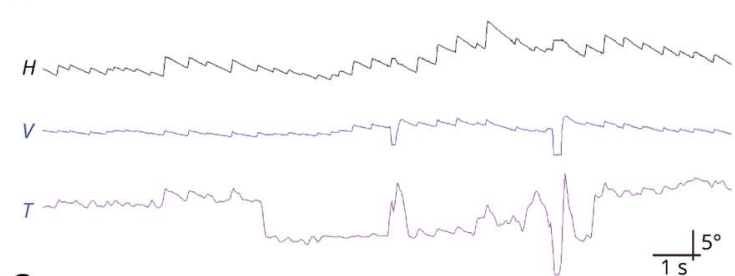

C

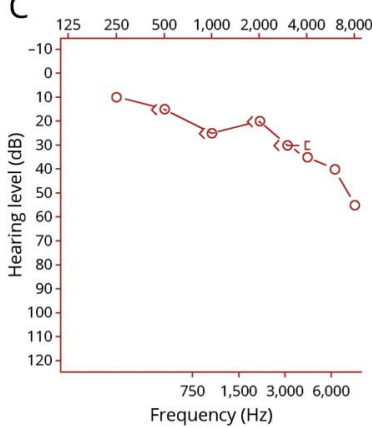

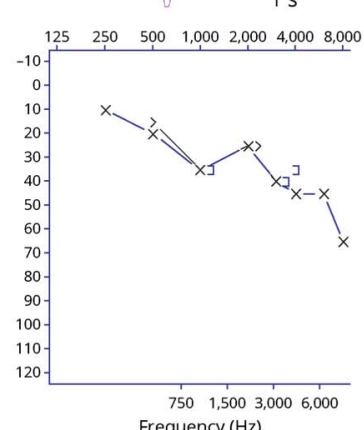

Frequency $(\mathrm{Hz})$
B

400 Right $\mathrm{HC}$ gain $=1.03$ Right $\mathrm{AC}$ gain $=1.07$ Right $\mathrm{PC}$ gain $=0.93$
- Head

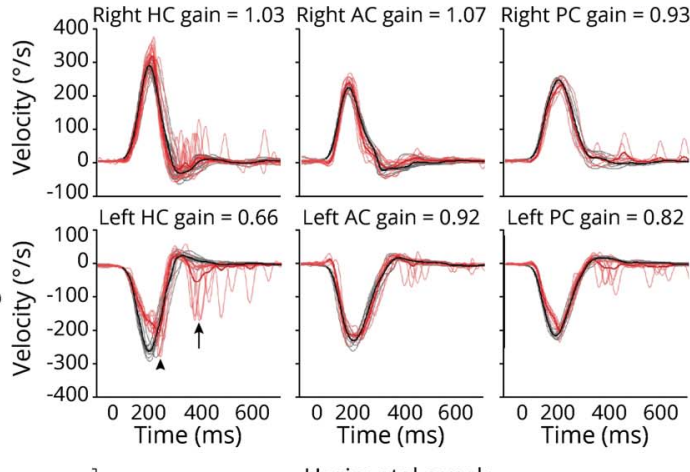

Horizontal canals

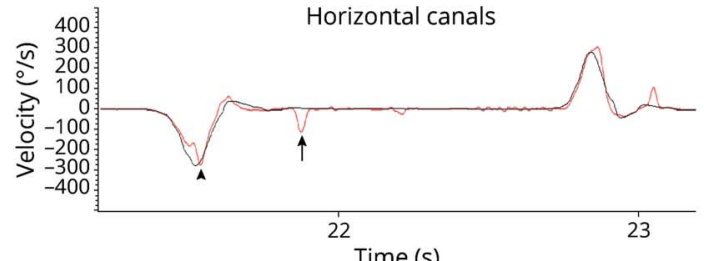

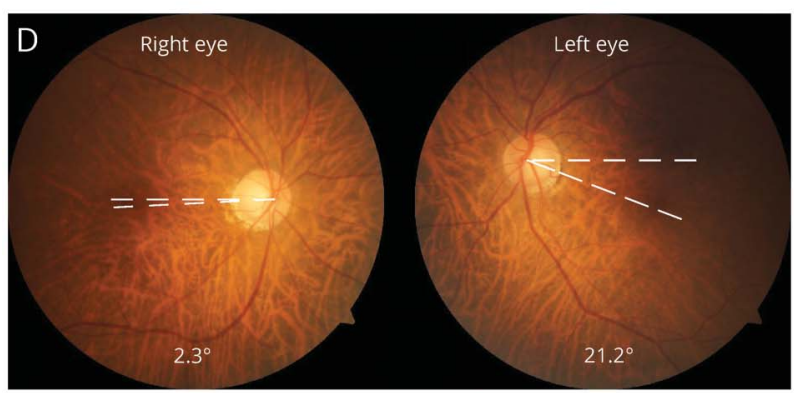

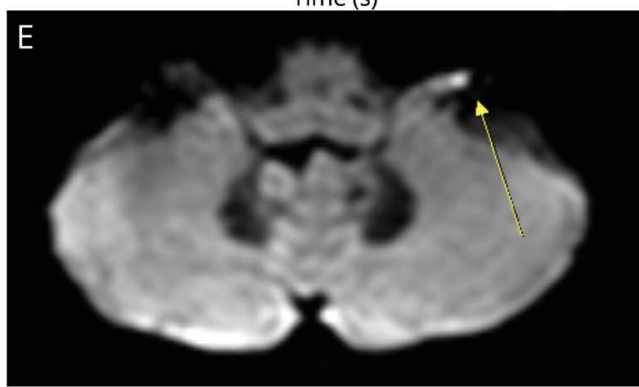

$\mathrm{F}$

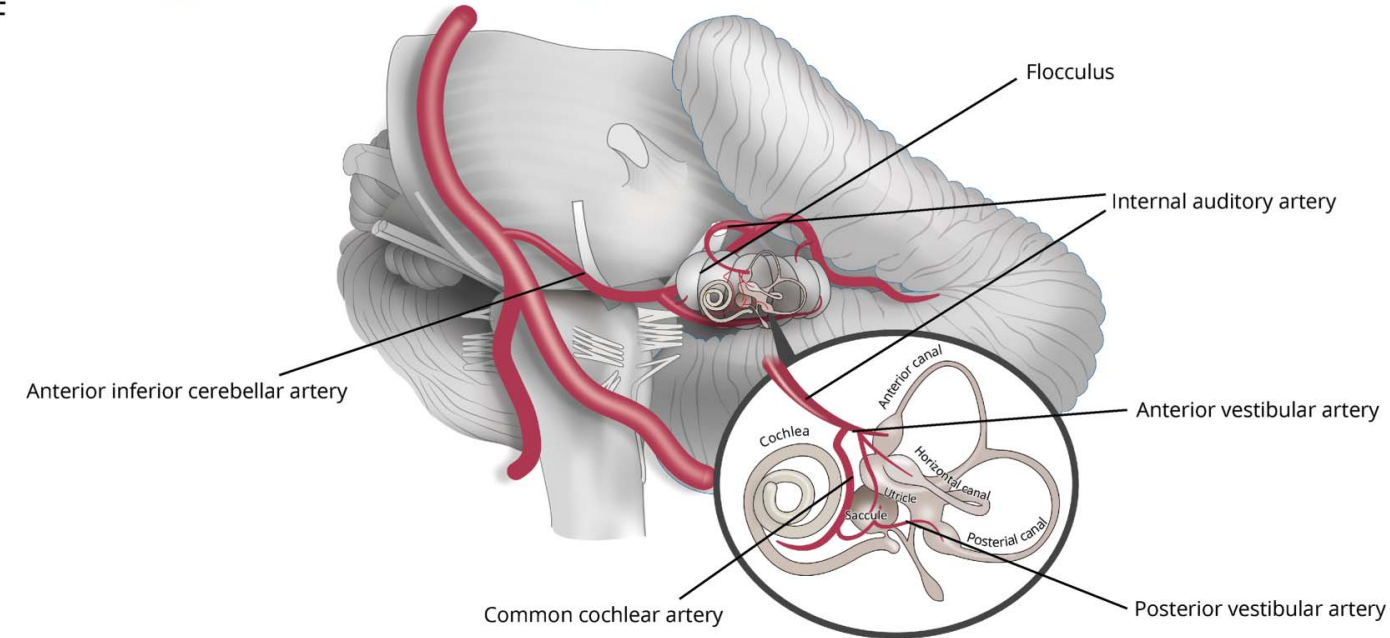

(A) Video-oculography shows spontaneous nystagmus beating rightward, upward, and clockwise (the upper poles of the eyes beating to the patient's right ear). Without visual fixation in darkness. Upward deflection represents rightward, upward, and clockwise eye motion in each video-oculography recording. (B) Video head-impulse tests show a decreased gain and covert (black arrowhead) and overt saccades (black arrow) for the left horizontal canal (HC) along with small corrective saccades for the right HC. (C) Pure-tone audiometry revealed bilateral sensorineural hearing loss with a pure tone average at $22.5 \mathrm{~dB}$ in the right and $36.3 \mathrm{~dB}$ in the left. (D) Fundus photography shows extorsion of the left eye (normal range $0^{\circ}-12.6^{\circ} ;$ a negative value indicates intorsion). (E) Diffusionweighted images (Intera, Philips Medical Systems) 4 hours from the onset of vertigo disclosed a discrete lesion in the left flocculus (arrow). (F) Illustration of the vascular supply to the flocculus and labyrinth that share a common arterial supply from the anterior inferior cerebellar artery. $\mathrm{AC}=$ anterior canal; $\mathrm{H}=$ horizontal position of the left eye; $\mathrm{PC}=$ posterior canal; $\mathrm{T}=$ torsional position of the left eye; $\mathrm{V}=$ vertical position of the left eye.

\section{Discussion}

Our patient with acute unilateral floccular infarction documented with MRIs masqueraded as vestibular neuritis to exhibit horizontal-torsional nystagmus beating away from the lesion side, ipsilesional canal paresis and abnormal HITs, and ipsiversive ocular torsion and SVV tilt along with subtle auditory symptoms. 


\section{Concomitant Labyrinthine and Cerebellar Infarction}

Given the common vascular supply to the cerebellar flocculus and inner ear, mostly from the anterior inferior cerebellar artery (AICA; Figure, F), ${ }^{1,2}$ findings of acute unilateral peripheral vestibulopathy may be ascribed to concomitant labyrinthine infarction that is hardly visualized with current imaging technique in our patient. The diagnosis of labyrinthine infarction is usually made when patients show combined loss of hearing and peripheral vestibular function in association with brainstem or cerebellar infarction in the territory of AICA. ${ }^{3}$ Occasionally, diffusion-weighted images (DWI) can also visualize an infarction directly involving the vestibulocochlear nerve or the labyrinth. ${ }^{4}$ Given the common vascular supply of the vestibulocochlear nerve and the labyrinth, ${ }^{1}$ infarctions are hardly expected to involve the vestibular nerve only and spare the cochlear nerve. ${ }^{2}$ Indeed, only $4 \%$ of patients with infarction in the territory of AICA present with acute vestibulopathy in isolation. ${ }^{3}$ However, as in our patient, the auditory symptoms may not be striking in embolic labyrinthine infarction when the anterior vestibular artery is preferentially involved. ${ }^{1,5}$ Indeed, laboratory evaluation showed predominant involvement of the HC. Given the normal angiogram, steno-occlusion of the proximal portion of the AICA and subsequent recanalization or embolism may be presumed as the mechanism.

\section{Differentiation of Labyrinthine Infarction From Vestibular Neuritis}

The diagnostic hallmarks of vestibular neuritis are spontaneous contralesional horizontal-torsional nystagmus, positive HITs for the ipsilesional canals, and ipsilesional canal paresis. Unlike Ramsay-Hunt syndrome or labyrinthitis that can show swelling or gadolinium enhancement in the vestibular nerve or labyrinth, ${ }^{6}$ conventional MRIs of the inner ear are almost always normal in vestibular neuritis. ${ }^{7}$ As such, the diagnostic utility of MRIs is limited unless using high-dose gadolinium or a 4-hour delayed 3D fluid-attenuated inversion recovery images. ${ }^{8}$ Thus, the diagnosis of labyrinthine infarction should be based on findings of history taking and clinical evaluation. Absence of antecedent infection and the hyperacute onset of vertigo are also atypical for vestibular neuritis.

\section{Catching the Subtle Auditory and Central Ocular Motor Signs}

Although the 3-item bedside eye movement screening head impulse, nystagmus, test of skew (HINTS) shows excellent sensitivity, it can be misleading in AICA infarction. ${ }^{9}$ Moreover, DWI often fails to detect the labyrinthine infarction, which can be a harbinger of AICA infarction. ${ }^{10}$ Thus, scrutinized neurotologic evaluation is important for diagnosing infarction involving the labyrinth and cerebellum. In our patient, the diagnosis of labyrinthine infarction was challenging because the auditory symptoms were subtle and transient. Patients may not notice hearing impairments during an attack of vertigo when the hearing loss is subtle. ${ }^{11}$ In this case, the finger rub test may help detect asymmetric hearing at bedside. $^{12}$ Because HINTS may fail to detect labyrinthine infarction, ${ }^{13}$ detection of hearing loss using the finger rub test (HINTS-plus) is important for diagnosing vascular inner ear damage. $^{12}$

Even though floccular infarction was found on MRI, our patient did not show ipsilesional spontaneous nystagmus, GEN, impaired smooth pursuit, or increased gain of the VOR during rotatory chair test, which are ocular motor signs indicating floccular dysfunction. However, the small corrective saccades for the contralesional right $\mathrm{HC}$ may be ascribed to a partial involvement of the left flocculus or adaptation to the labyrinthine infarction. ${ }^{14}$

A thorough history taking and neurotologic evaluation are important for differentiating labyrinthine infarction from inflammatory disorders involving the labyrinth.

\section{Study Funding}

This study was supported by the Korea Health Technology R\&D Project through the Korea Health Industry Development Institute (KHIDI), funded by the Ministry of Health and Welfare (HI14C3477), and Basic Science Research Program through the National Research Foundation of Korea (NRF) funded by the Ministry of Education, Science and Technology (no. NRF-2016R1D1A1B04935568).

\section{Disclosure}

H.W. Nam, D. Yoo, S.-U. Lee, J.-Y. Choi, and S. Yu report no disclosures relevant to the manuscript. J.-S. Kim serves as an Associate Editor of Frontiers in Neuro-otology and on the editorial boards of the Journal of Clinical Neurology, Frontiers in Neuro-ophthalmology, Journal of Neuro-ophthalmology, Journal of Vestibular Research, Journal of Neurology, and Medicine. Go to Neurology.org/ $\mathrm{N}$ for full disclosures.

Appendix Authors

\begin{tabular}{lll}
\hline Name & Location & Contribution \\
\hline $\begin{array}{l}\text { Hyun- } \\
\text { Nook, MD }\end{array}$ & $\begin{array}{l}\text { Department of Neurology, } \\
\text { Korea University Medical } \\
\text { Center, Seoul, South Korea }\end{array}$ & $\begin{array}{l}\text { Drafting/revision of the } \\
\text { manuscript for content, } \\
\text { including medical writing for } \\
\text { content; major role in the } \\
\text { acquisition of data; analysis or } \\
\text { interpretation of data }\end{array}$ \\
\hline $\begin{array}{l}\text { Dallah } \\
\text { Yoo, MD }\end{array}$ & $\begin{array}{l}\text { Kepartment of Neurology, } \\
\text { Kospital, Seoul, South Korea }\end{array}$ & $\begin{array}{l}\text { Major role in the acquisition of } \\
\text { data; analysis or } \\
\text { interpretation of data }\end{array}$ \\
\hline $\begin{array}{l}\text { Sun-Uk } \\
\text { Lee, MD }\end{array}$ & $\begin{array}{l}\text { Department of Neurology, } \\
\text { Korea University Medical } \\
\text { Center, Seoul, South Korea }\end{array}$ & $\begin{array}{l}\text { Drafting/revision of the } \\
\text { manuscript for content, } \\
\text { including medical writing for } \\
\text { content; major role in the } \\
\text { acquisition of data; study } \\
\text { concept or design; analysis or } \\
\text { interpretation of data }\end{array}$ \\
\hline $\begin{array}{l}\text { Jeong- } \\
\text { MD, PhD }\end{array}$ & $\begin{array}{l}\text { Deopartment of Neurology, } \\
\text { Seoul National University } \\
\text { Korea of Medicine, South }\end{array}$ & $\begin{array}{l}\text { Analysis or interpretation of } \\
\text { data }\end{array}$ \\
\hline
\end{tabular}

Continued 
Appendix (continued)

\begin{tabular}{lll}
\hline Name & Location & Contribution \\
\hline $\begin{array}{l}\text { Sungwook } \\
\text { Yu, MD, } \\
\text { PhD }\end{array}$ & $\begin{array}{l}\text { Department of Neurology, } \\
\text { Korea University Medical } \\
\text { Center, Seoul, South Korea }\end{array}$ & $\begin{array}{l}\text { Analysis or interpretation of } \\
\text { data }\end{array}$ \\
\hline $\begin{array}{l}\text { Ji-Soo Kim, } \\
\text { MD, PhD }\end{array}$ & $\begin{array}{l}\text { Department of Neurology, } \\
\text { Seoul National University } \\
\text { College of Medicine, South } \\
\text { Korea }\end{array}$ & $\begin{array}{l}\text { Analysis or interpretation of } \\
\text { data }\end{array}$ \\
& & \\
\end{tabular}

\section{References}

1. Kim J, Lopez I, DiPatre P, Liu F, Ishiyama A, Baloh R. Internal auditory artery infarction: clinicopathologic correlation. Neurology. 1999;52(1):40-44.

2. Hotson JR, Baloh RW. Acute vestibular syndrome. N Engl J Med. 1998;339(1): 680-685.

3. Lee H, Kim JS, Chung E-J, et al. Infarction in the territory of anterior inferior cerebellar artery spectrum of audiovestibular loss. Stroke. 2009;40(12):3745-3751.

4. Choi SY, Park JH, Kim HJ, Kim JS. Vestibulocochlear nerve infarction documented with diffusion-weighted MRI. J Neurol. 2015;262(5):1363-1365
5. Liqun Z, Park KH, Kim HJ, Lee SU, Choi JY, Kim JS. Acute unilateral audiovestibulopathy due to embolic labyrinthine infarction. Front Neurol. 2018;9:311.

6. Iwasaki H, Toda N, Takahashi M, et al. Vestibular and cochlear neuritis in patients with Ramsay Hunt syndrome: a Gd-enhanced MRI study. Acta Otolaryngol. 2013; 133(4):373-377.

7. Strupp M, Jäger L, Müller-Lisse U, Arbusow V, Reiser M, Brandt T. High resolution Gd-DTPA MR imaging of the inner ear in 60 patients with idiopathic vestibular neuritis: no evidence for contrast enhancement of the labyrinth or vestibular nerve. $J$ Vestib Res. 1998;8(6):427-433.

8. Byun H, Chung JH, Lee SH, Park CW, Park DW, Kim TY. Clinical value of 4-hour delayed gadolinium-enhanced 3D FLAIR MR images in acute vestibular neuritis. Laryngoscope. 2018;128(8):1946-1951.

9. Carmona S, Martínez C, Zalazar G, et al. The diagnostic accuracy of truncal ataxia and HINTS as cardinal signs for acute vestibular syndrome. Front Neurol. 2016;7:125.

10. Kim JS, Cho KH, Lee H. Isolated labyrinthine infarction as a harbinger of anterior inferior cerebellar artery territory infarction with normal diffusion-weighted brain MRI. J Neurol Sci. 2009;278(1-2):82-84.

11. Lee $\mathrm{H}$. Recent advances in acute hearing loss due to posterior circulation ischemic stroke. J Neruol Sci. 2014;338(1-2):23-29.

12. Newman-Toker DE, Curthoys IS, Halmagyi GM. Diagnosing stroke in acute vertigo: the HINTS family of eye movement tests and the future of the "Eye ECG." Semin Neurol. 2015;35(5):506-521.

13. Newman-Toker DE, Kerber KA, Hsieh YH, et al. HINTS outperforms ABCD 2 to screen for stroke in acute continuous vertigo and dizziness. Acad Emerg Med. 2013;20:986-996.

14. Park HK, Kim JS, Strupp M, Zee DS. Isolated floccular infarction: impaired vestibular responses to horizontal head impulse. J Neurol. 2013;260(6):1576-1582.

\section{Share Your Artistic Expressions in Neurology 'Visions'}

AAN members are urged to submit medically or scientifically related artistic images, such as photographs, photomicrographs, and paintings, to the "Visions" section of Neurology $y^{\oplus}$. These images are creative in nature, rather than the medically instructive images published in the NeuroImages section. The image or series of up to six images may be black and white or color and must fit into one published journal page. Accompanying description should be 100 words or less; the title should be a maximum of 140 characters including spaces and punctuation.

Please access the Author Center at NPub.org/authors for full submission information.

\section{Disputes \& Debates: Rapid Online Correspondence}

The editors encourage comments on recent articles through Disputes \& Debates:

Access an article at Neurology.org/ $N$ and click on "MAKE COMMENT" beneath the article header.

Before submitting a comment to Disputes \& Debates, remember the following:

- Disputes \& Debates is restricted to comments about articles published in Neurology within 6 months of issue date

- Read previously posted comments; redundant comments will not be posted

- Your submission must be 200 words or less and have a maximum of 5 references; the first reference must be the article on which you are commenting

- You can include a maximum of 5 authors (including yourself) 


\section{Neurology}

\section{Pearls \& Oy-sters: Labyrinthine Infarction Mimicking Vestibular Neuritis \\ Hyun-Wook Nam, Dallah Yoo, Sun-Uk Lee, et al.}

Neurology 2021;97;787-790 Published Online before print May 27, 2021

DOI 10.1212/WNL.0000000000012297

This information is current as of May 27, 2021

\section{Updated Information \& Services}

References

Subspecialty Collections

\section{Permissions \& Licensing}

Reprints including high resolution figures, can be found at: http://n.neurology.org/content/97/16/787.full

This article cites 14 articles, 2 of which you can access for free at: http://n.neurology.org/content/97/16/787.full\#ref-list-1

This article, along with others on similar topics, appears in the following collection(s):

All Neurotology

http://n.neurology.org/cgi/collection/all_neurotology

Audition

http://n.neurology.org/cgi/collection/audition

Infarction

http://n.neurology.org/cgi/collection/infarction

Tinnitus

http://n.neurology.org/cgi/collection/tinnitus

Vertigo

http://n.neurology.org/cgi/collection/vertigo

Information about reproducing this article in parts (figures,tables) or in its entirety can be found online at:

http://www.neurology.org/about/about_the_journal\#permissions

Information about ordering reprints can be found online:

http://n.neurology.org/subscribers/advertise

Neurology ${ }^{\circledR}$ is the official journal of the American Academy of Neurology. Published continuously since 1951, it is now a weekly with 48 issues per year. Copyright () 2021 American Academy of Neurology. All rights reserved. Print ISSN: 0028-3878. Online ISSN: 1526-632X.

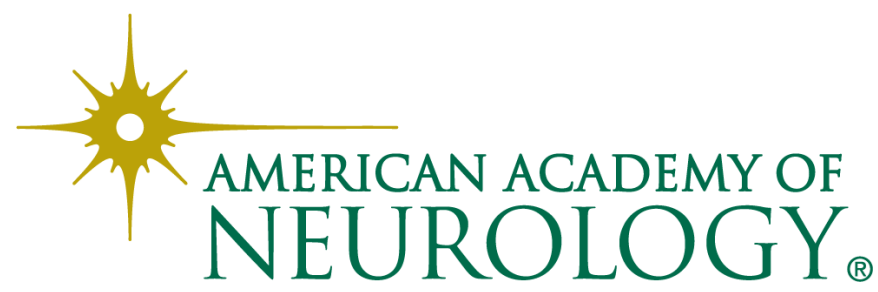

